\title{
Comparitive Genome Sequence Analysis of Bovine Lymphocyte Antigen BoLA DRB3.2 Alleles in Deoni and Ongole (Bos indicus) Cattle Breeds of India
}

\author{
R. Saravanan, N. Murali', A.K. Thiruvenkadan'1, D.N. Das
}

10.18805/IJAR.B-4357

\begin{abstract}
Background: India, a major livestock region of the Asian countries is rich in animal genetic resources having special qualities of hardy nature, resistance to many diseases and adopted to adverse climatic conditions. The cattle MHC, Bovine Lymphocyte Antigen DRB3 (BoLA-DRB3) is considered to be a major gene linked with disease resistance traits of Indian cattle.

Methods: The present study was carried out to sequence the BoLA-DRB3.2 alleles in Deoni and Ongole breeds of Indian cattle. PCR RFLP analysis of the BoLA-DRB3.2 alleles in Deoni $(n=51)$ and Ongole $(n=60)$ cattle using three different restriction enzymes Rsal, Bst $Y$ and HaellI to find out the possible restriction pattern. Based on the combined allelic patterns, each sample was further analyzed by PCR- SBT technique to detect the SNP variations present in BoLA-DRB3.2 alleles.

Result: The PCR RFLP analysis revealed that the highest frequent alleles are ${ }^{*} 6(0.216)$ and ${ }^{*} 15(0.225)$ in Deoni and Ongole breeds of cattle, respectively. The second-highest frequency was observed for $B o L A$ alleles ${ }^{*} 11$ and ${ }^{*} 6$ which were present at a frequency of 0.167 and 0.200 in Deoni and Ongole breeds of cattle, respectively. To get the complete picture of polymorphic pattern of BoLADRB3.2 allele direct sequencing was carried out for each plymorphic pattern. The interesting feature noticed in the Ongole breed was that at position 91 and 133 of the sequence, it had both $A$ and $G$ nucleotides in contrast to Bos taurus breed, which had only TT nucleotides. The sequence analysis of BoLA-DRB3 exon 2 between two breeds revealed that there are numerous variations in exon 2, whatever variation, that lead to different mobility shift and band pattern in gels. Deoni and Ongole breeds of cattle had similar variations at positions $94,134,211,235$ and 258noticed due to the unique nature of native breeds.
\end{abstract}

Key words: BoLA-DRB3, Deoni, Diversity, Ongole, Sequence-based typing, Zebu cattle.

\section{INTRODUCTION}

There are 50 recognized native breeds of cattle in India having special qualities of hardy nature, resistance to many diseases and adopted to adverse climatic condition. Geneticists and evolutionary biologists have great interest to identify the variation of Bovine Leukocyte Antigen (BoLA) because of its variability patterns reflected different evolutionary processes viz., adaptation to climate, natural selection and genetic drift (Goszczynski et al., 2014; Takeshima et al., 2014). Several studies have shown that high level of BoLA diversity might be responsible for disease resistance especially pathogen recognition and presentation to lymphocyte (Borg et al., 2011; Newhouse and Balakrishnan, 2015). Even though, the Bos indicus cattle known for its disease resistance, very few studies have been carried out on the characterization of BoLA$D R B 3$ genetic diversity and its structure.

Bovine Lymphocyte Antigen DRB3 (BoLA-DRB3) is a bovine Major Histocompatibility complex (MHC) and its polymorphism highly correlated with many disease resistance traits in Indian cattle breed.BoLA-DRB3 is the potential genetic markers and up to date more than 136 different alleles have been reported (Van Eijk et al., 1992; Gelhaus et al., 1995; Maillard et al., 1999; do Nascimento et al., 2006; Maccari et al., 2017).Several studies have shown that decreased MHC variability might be caused by population bottlenecks (Mason et al., 2011; Zhang et al.,
Department of Animal Genetics and Breeding, Veterinary College and Research Institute, Tamil Nadu Veterinary and Animal Sciences University, Namakkal-637 002, Tamil Nadu, India.

${ }^{1}$ Genetics Lab., National Dairy Research Institute, Southern Campus, Adugodi, Bangalore-560 030, Karnataka, India.

Corresponding Author: R. Saravanan, Department of Animal Genetics and Breeding, Veterinary College and Research Institute, Tamil Nadu Veterinary and Animal Sciences University, Namakkal637 002, Tamil Nadu, India. Email: mrsagb@gmail.com

How to cite this article: Saravanan, R., Murali, N., Thiruvenkadan, A.K. and Das, D.N. (2021). Comparitive Genome Sequence Analysis of Bovine Lymphocyte Antigen BoLA DRB3.2 Alleles in Deoni and Ongole (Bos indicus) Cattle Breeds of India. Indian Journal of Animal Research. DOI: 10.18805/IJAR.B-4357.

Submitted: 05-11-2020 Accepted: 28-11-2020 Online: 02-02-2021

2016). Bovine leukocyte antigens ( $B o L A)$ have been used as disease markers and immunological traits in cattle due to their primary role in pathogen recognition by the immune system (David et al.,2020). Hence, a study was taken up to characterize BoLA-DRB3.2 alleles in the native animals of Deoni and Ongole breeds of cattle. These results provide an insight into $\mathrm{MHC}$ evolution and contribute toward efforts at describing bovine MHC diversity according to breed and location. Hence, this study was aimed at determining 
Comparitive Genome Sequence Analysis of Bovine Lymphocyte Antigen BoLA DRB3.2 Alleles in Deoni and Ongole...

variability of BoLA DRB3 through direct sequencing in Indian Ongole and Deoni cattle breeds and compared to sequence of Taurine breeds.

\section{MATERIALS AND METHODS}

Genomic DNA was isolated from the whole blood of 51 Deoni and 60 Ongole breeds of cattle as per the method of Miller et al. (1988) with slight modifications. Hemi-nested PCR was used for the amplification of the exon 2 (284 bp) of the BoLA$D R B 3$ gene, as described by Van Eijk et al. (1992) with the primers sequence of HL030 5'- ATC CTC TCT CTG CAG CAC ATT TCC-3' , HL031 5' - TTT AAT TCG CGC TCA CCT CGC CGC T-3' and HL03' 5' - TCG CCG CTG CAC AGT GAA ACT CTC-3'. In the first round of PCR, amplification was performed with $\mathrm{HLO} 30$ and HLO31 primers with an initial denaturation step of 5 minutes at $94^{\circ} \mathrm{C}$ followed by 10 cycles of 1 minute at $94^{\circ} \mathrm{C}, 2$ minutes at $60^{\circ} \mathrm{C}, 1$ minute at $72^{\circ} \mathrm{C}$ and a final extension of 5 minutes at $72^{\circ} \mathrm{C}$. After the first round, a semi-nested second round PCR reaction was carried out with $1 \mu \mathrm{l}$ of the first-round PCR product as DNA template, HLO30 and HLO32 primers with the same PCR condition except the annealing temperature $65.5^{\circ} \mathrm{C}$ for $30 \mathrm{~s}$.

In this study, the PCR-RFLP analysis was carried out with three different restriction enzymes Rsal, BstYl and Haell in Ongole, and Deoni cattle to find out the possible restriction pattern and restriction patterns were combined to determine the allelic pattern as per the BoLA nomenclature (Russell et al., 1997) as reported in the $B o L A$ nomenclature homepage (http:// www.projects.roslin.ac.uk/BoLA/DRB3pcr.htmltable). Results obtained for PCR-RFLP analysis are presented in Table 1. Allele frequencies were determined by $\mathrm{Hi}=\sum \mathrm{ni} / \mathrm{N}$, where $H^{i}$ is the frequency for allele $i, \Sigma n_{i}$ is the sum of alleles in $\mathrm{i}^{\text {th }}$ population, and $\mathrm{N}$ is the total number of alleles in the population. Further, Fishers exact test was performed to verify the difference in frequencies between the breeds. Subsequently the data was subjected to z- test with Bonferroni correction for pair wise comparisons $(P<0.05)$ of proportion (Ryman and Jorde, 2001).

The positive amplified PCR products showing different allelic patterns were further analyzed by PCR- SBT technique to detect the SNP variations present in BoLA-DRB3.2 alleles. One sample from each PCR RFLP pattern was selected and sequenced using the forward and reverse primer to detect the variations at the nucleotide level. Sequencing was performed on an automated sequencer ( $\mathrm{BBI}$ prism) using Sangers's dideoxy chain termination method at SciGenom, Cochin. Clustal Omega is a new Multiple Sequence Alignment (MSA) program that uses seeded guide trees and HMM profile-profile techniques to generate alignments between three or more sequences (Sievers et al., 2011). MSA of BoLA-DRB3.2 alleles was done using the DNA star Lasergene MegAlign program (DNASTAR CoreSuit10 software, Inc. USA).

\section{RESULTS AND DISCUSSION}

A $284 \mathrm{bp}$ fragment of the BoLA-DRB3 gene, composed of
$10 \mathrm{bp}$ of the $5^{\prime}$ intron, $267 \mathrm{bp}$ of exon 2 , and $7 \mathrm{bp}$ of the $3^{\prime}$ intron of chromosme 23, was amplified. PCR-RFLP analysis of the BoLA-DRB3.2 alleles in the present study was determined using three restriction pattern of as per BoLA nomenclature (Russell et al., 1997). Only 111 alleles were concluded for Deoni (51) and Ongole (60) from established restriction pattern of 150 animals. BoLA alleles were unambiguously identified only for 111 animals and the haplotype discriminations were not possible in the remaining animals as they were heterozygous for more than one restriction enzyme and due to the non-availability of production data. Similar findings were reported by Starkenburg et al. (1997) and Miretti et al. (2001).

The major alleles of BoLA-DRB3.2, which had a frequency of 0.05 and above are shown in Table 1 and frequency are significantly higher $(\mathrm{P}<0.05)$ based on the $\chi^{2}$ test. The total number of alleles identified in both breeds was twenty-nine with frequencies ranging from 0.008 to 0.225 . Of these total alleles detected, all 29 alleles were similar to those reported in earlier studies (Van Eijk et al., 1992; Gelhaus et al., 1995; http://www.projects.roslin.ac.uk/BoLA/ $D R B 3 p c r . h t m l t a b l e)$.

The PCR RFLP results showed that the highest frequent allele in Deoni and Ongole breeds was DRB3.2*6 (21.6 per cent) and $D R B 3.2^{*} 15$ (22.5 per cent), respectively. A high degree of polymorphism in exon 2 of $B o L A-D R B 3$ by the PCR-RFLP technique was also revealed by Van Eijk et al. (1992). The second-highest number of allele BoLA alleles ${ }^{*} 11$ and ${ }^{*} 6$ which were present at a frequency of 0.167 and 0.200 in Deoni and Ongole breeds of cattle, respectively. Of the 22 identified alleles detected in Deoni, nine alleles (BoLA-DBB3.2*6, *11, *9, *15, *20 *23, *34, *47 and *51) represented 78.4 per cent of total allelic frequencies. Whereas in Ongole, 77.5 per cent of allelic frequencies were covered by the seven BoLA-DRB3.2 ( ${ }^{*} 15,{ }^{*} 6,{ }^{*} 12,{ }^{*} 13,{ }^{*} 23$, ${ }^{*} 31$ and ${ }^{*} 47$ ) alleles. Based on the multiple allelic frequency comparison between two breeds, three allelic frequencies showed a statistically significant $(\mathrm{P}<0.05)$ differences, after Bonferroni correction, the results clearly indicate that alleles DRB3.2 ${ }^{*} 9$ and ${ }^{*} 11$ are unique to Deoni and the allele DRB3.2*15 are unique to the Ongole breed of cattle (Table 1).

These two populations studied were not homogenous with respect to their allelic composition and there was a significant difference in their allele frequencies. Alleles ${ }^{*} 19$, *25, *35, *38, *41, *46 and *54 in Deoni and alleles *3, *8, ${ }^{*} 12,{ }^{*} 13,{ }^{*} 16,{ }^{*} 32$ and ${ }^{*} 42$ in Ongole were unique to their respective breeds. Duangjinda et al. (2009) revealed that the most frequently detected alleles of Holstein $x$ Zebu were $D R B{ }^{*} 16,{ }^{*} 51,{ }^{*} 23,{ }^{*} 11,{ }^{*} 8$ and ${ }^{*} 1$ accounting for 61.12 per cent of the alleles. Results of the present study indicate that the $B o L A-D R B 3$ exon 2 is highly polymorphic both in Deoni and Ongole (Bos indicus) breeds of cattle.

Several authors reported that the high degree of polymorphism in the BoLA-DRB3.2 in various breeds of cattle. For example, in a study carried out by Sharif et al. (1998), the highest frequent allele was DRB3.2 *7 among 
the six the most common alleles of BoLA-DRB3.2 ${ }^{*} 7,{ }^{*} 10$, *17, *21, *28 and *32 in 66 Jersey cows. But it was not observed by Gilliespie et al. (1999) where he detected the BoLA-DRB3.2 *8, *10, *15, *21, *36 and *ibe as the most frequent alleles in same Jersey breeds. This is comparable to the observation of our findings in these two indigenous cattle breeds.

Dietz et al. (1997) carried out polymorphism studies on the BoLA-DRB3.2 locus in a population of 127 Holstein cows. They observed that BoLA-DRB3.2 *8, *11, *16, *22, *23 and *24 were the six most frequently $(70.3$ per cent) detected alleles. In another study, on Holstein animals $(n=835)$, Sharif et al. (1998) observed that 7 alleles of BoLA-DRB3.2 *3, *8, ${ }^{*} 11,{ }^{*} 16,{ }^{*} 22,{ }^{*} 23$ and ${ }^{*} 24$ represented 88.7 per cent of the total alleles. But in contrast to our observations, in Argentine Creole cattle $(n=194), 68$ per cent of the gene frequencies were represented by 5 alleles (DRB 3.2 *15, *18, *20, *24 and $* 27$ (Giovambattista et al., 1996). Approximately 70 per cent of the alleles in the Japanese Shorthorn cattle were accounted for by 6 alleles BoLA-DRB3.2 *8, *9, *21, *27, *7and *24 (Takeshima et al., 2002). Therefore, it could be observed that differences in allelic frequencies existed among different breeds of cattle. The present study on native breeds of Deoni and Ongole clearly indicates that these were allelic variations in the $B O L A$ region which are distinctively different from each other.

The amplified sequences exon 2 of BoLA-DRB3 was $284 \mathrm{bp}$ in length in two different breeds. Nucleotide variation of the Bos indicus cattle was compared to the BoLA reference sequence (NM_001012680) of Bos taurus cattle. There are numerous variations in Bos indicus cattle breeds when compared to the Taurine cattle breed. The interesting feature noticed in Ongole and Deoni breed was that at positions 92, 134 and 258 base pair level, it had both A, G and $C$ nucleotide in contrast to the $B o L A$ reference sequence (NM_001012680) of Bos taurus cattle, which had only T nucleotides (Fig. 1). Further, certain nucleotide variation in the position of the $11(\mathrm{C}-\mathrm{G}), 34(\mathrm{~T}-\mathrm{C}), 40(\mathrm{G}-\mathrm{A}), 181(\mathrm{~T}-\mathrm{C})$, 183(C-S), 211(C-G), 214(A-G), 260(T-G) and 275(T-G) are unique to Ongole cattle breed, which was absent in both Deoni and Taurine animals but they are sharing similar type of sequences. Even though certain nucleotide variations at 201(T-W), 212(A-G), 213 (A-G), 233(G-C), 235 to 237 (GTG -TAC) and 257(G-T) are unique to the Deoni cattle breed when compare to Bos taurus cattle, but few Ongole animals also sharing the same variations. The multiple Sequence Alignment sequence variations of Bos indicus breeds confirmed the different combinations of RFLP patterns. Therefore, all these variations prove the existence of heterozygosity in BoLA-DRB3.2 alleles in Indian cattle breeds. Further, the presence of both nucleotides in the case of Ongole and Deoni may be specific for Indian inheritance.

The major change of $\mathrm{T}$ nucleotide variations was confirmed by the Maximum Composite Likelihood Estimate of the Pattern of Nucleotide Substitution model (Table 2). For simplicity, the sum of $r$ values is made equal to 100 .
Rates of different transitional substitutions are shown in bold and those of transversionsal substitutions are shown in italics. The nucleotide frequencies are $21.27 \%(\mathrm{~A}), 18.47 \%$ $(\mathrm{T} / \mathrm{U}), 24.43 \%(\mathrm{C})$, and $35.83 \%(\mathrm{G})$. The transition/ transversion rate ratios are $\mathrm{k} 1=0.658$ (purines) and $\mathrm{k} 2=$ 1.353 (pyrimidines). The overall transition/transversion bias is $R=0.454$, where $R=\left[A^{*} G^{*} k 1+T^{*} C^{*} k 2\right] /\left[(A+G)^{*}(T+C)\right]$. This analysis involved 22 nucleotide sequences. All ambiguous positions were removed for each sequence pair (pairwise deletion option). There were a total of 287 positions in the final dataset. Evolutionary analyses were conducted in MEGA X (Kumar, 2018).

Both the breeds of cattle have similar variations at positions $94,134,211,235$ and 258 which is due to the unique nature of native breeds. The variations in nucleotides of BoLA-DRB3 exon2 were confirmed to similar findings of the ISAG BoLA Nomenclature Committee report (Russell et al., 1997).

Therefore this shows the prevalence of nucleotides $A$, G, G, TAC and C in exon 2 at positions 92, 134, 211, 235 and 258 , respectively in native breeds of cattle viz., Ongole and Deoni and their respective position and found to be highly conserved in Indian cattle breeds. This is comparable with the report of Rupp et al., (2007) that the lysine encoding allele $(A A)$ is highly prevalent in Bos indicus breeds. Similar polymorphic patterns were also detected in $25 \mathrm{BoLA}-D R B 3$

Table 1: Test of significance for allele frequencies of $B o L A-D R B 3.2$ alleles among the cattle.

\begin{tabular}{|c|c|c|}
\hline & breeds studied & \\
\hline DRB3.2 alleles & Deoni ${ }^{* *}(\mathrm{~N}=51)$ & Ongole ${ }^{* *}(\mathrm{~N}=60$ \\
\hline DRB3.2*6 & $0.216(22)$ & $0.200(24)$ \\
\hline DRB3.2*9 & $0.078(8)^{\mathrm{B}}$ & \\
\hline DRB3.2*11 & $0.167(17)^{\mathrm{B}}$ & \\
\hline DRB3.2*12 & & $0.092(11)$ \\
\hline DRB3.2*13 & & $0.108(13)$ \\
\hline DRB3.2*15 & & $0.225(27)^{\mathrm{A}}$ \\
\hline DRB3.2*23 & $0.059(6)$ & $0.075(9)$ \\
\hline DRB3.2*34 & $0.059(6)$ & \\
\hline DRB3.2*51 & $0.059(6)$ & \\
\hline Total & 6 & 6 \\
\hline
\end{tabular}

${ }^{* *} \mathrm{P}(<0.001)$; Deoni: $\chi^{2}=28.22, \mathrm{df}=5, \mathrm{p}=0.000033$; Ongole: $\chi^{2}=$ $21.89, \mathrm{df}=4, \mathrm{p}=0.0002$.

A, B $(P<0.05) Z$ - test with Bonferroni correction .

Table 2: Maximum Composite Likelihood Estimate of the Pattern of Nucleotide Substitution.

\begin{tabular}{ccccc}
\hline & $\mathrm{A}$ & $\mathrm{T}$ & $\mathrm{C}$ & $\mathrm{G}$ \\
\hline$A$ & - & 6.25 & 8.26 & 7.98 \\
$T$ & 7.19 & - & 11.18 & 12.12 \\
$C$ & 7.19 & 8.45 & - & 12.12 \\
$G$ & 4.74 & 6.25 & 8.26 & - \\
\hline
\end{tabular}

Each entry shows the probability of substitution $(r)$ from one base (row) to another base (column). 


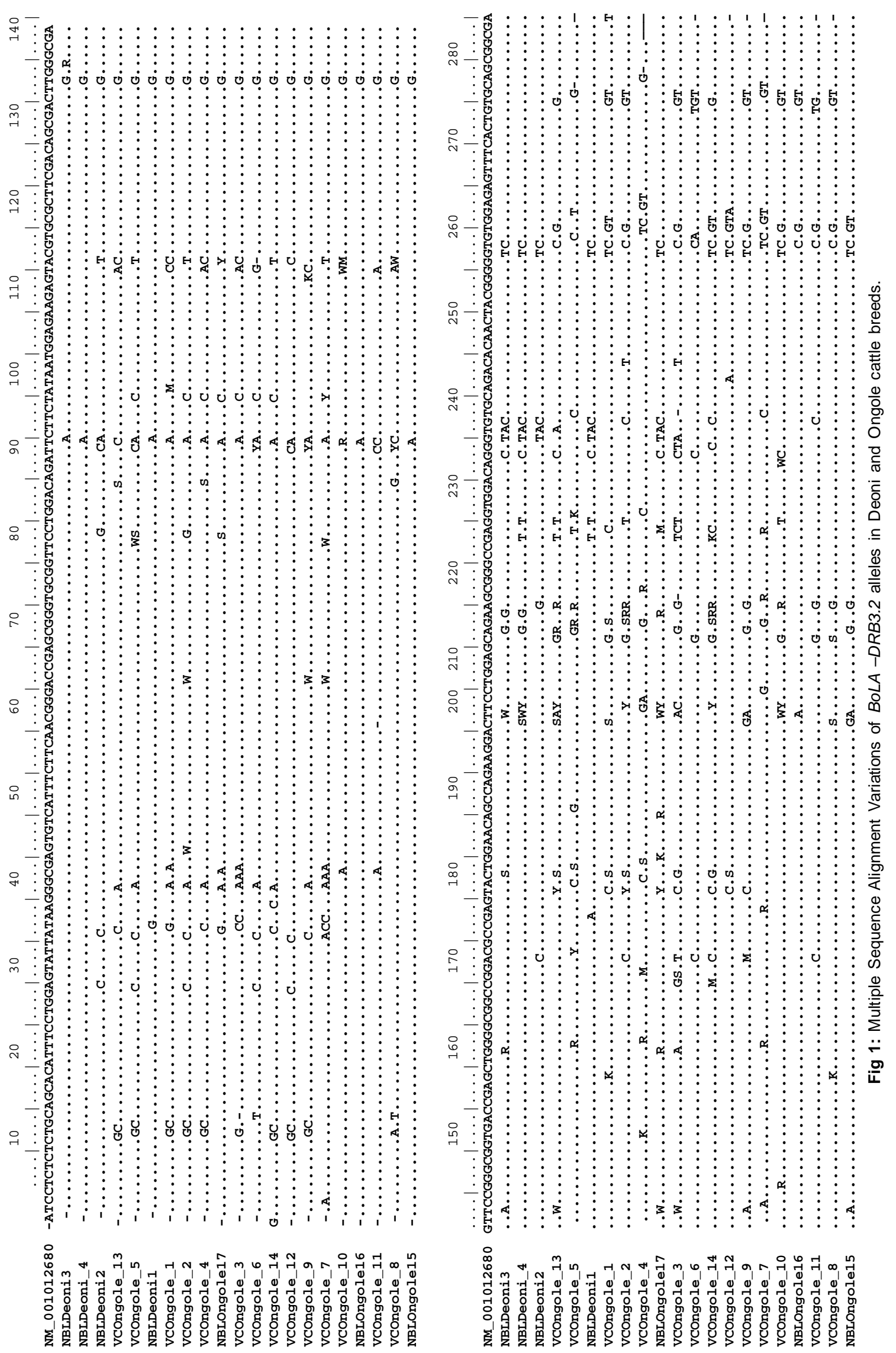




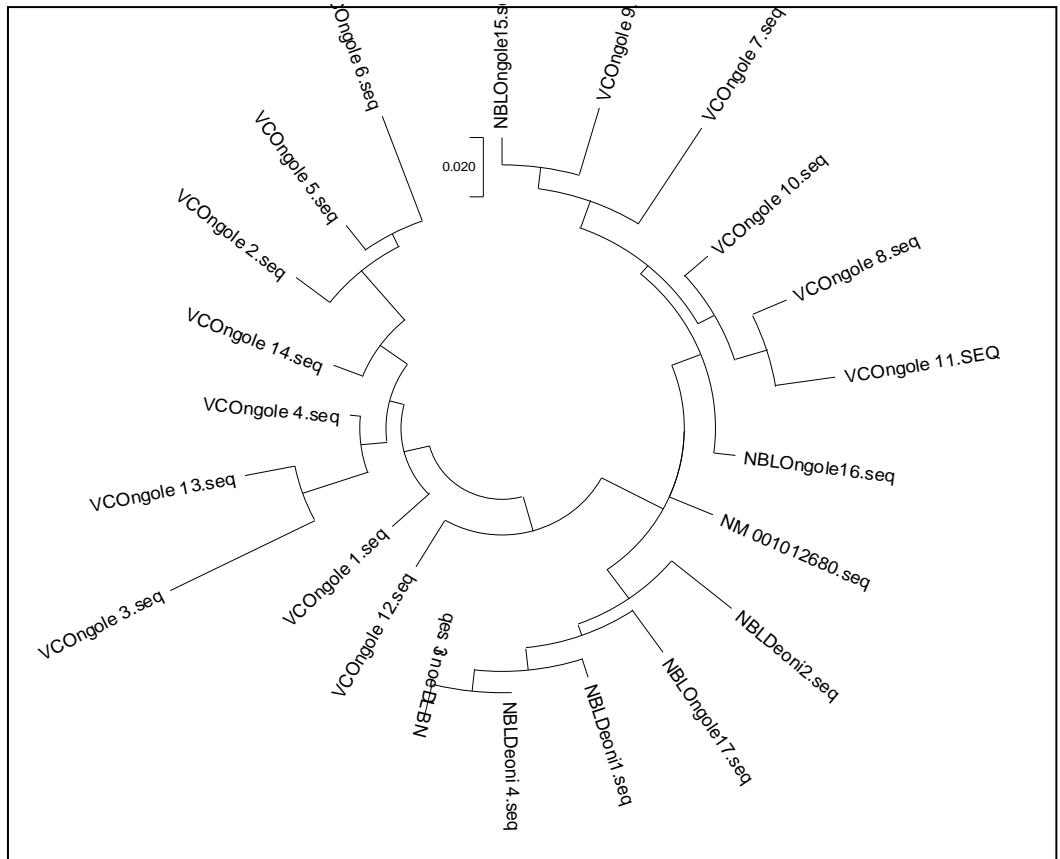

Fig 2: Phylogenetic tree of BoLA -DRB3.2 sequences of Deoni and Ongole cattle breeds.

alleles including 2 deletions in five Indian cattle breeds (De and Singh, 2006).

Further, the BoLA -DRB3.2 sequences of Deoni and Ongole cattle are showing the variation in their origin reflects through the groups of different clades of the phylogenetic tree (Fig 2). Phylogenetic tree analysis revealed that there are three major clusters each cluster indicates the three different nucleotide variations of breeds. Further, the observed sequences of Bos taurus and Bos indicus are showing the difference between different clads. All the Ongole nucleotides are almost similar in nature clustered in a single clad branched exclusively from the Taurine origin. The nucleotide variations present between Ongole and Deoni reflect in two separate clades of the phylogenetic tree, but the two clades branched from the Bos taurus cattle breed which indicates that the $B o L A$ sequence of Indicus is different from Taurine origin. The other clusters contain both Deoni and Ongole cattle sequences which show that both breeds have a certain sequence of common nucleotides. The different branches of the clad clearly indicate that the Bos indicus sequence is different from Taurine sequences.

The aligned nucleotide sequences have confirmed the uniqueness of aligned sequences with other sequences available in the NCBI gene bank database. The Multiple alignments of finally selected and trimmed sequences along with the $B o L A$ Consensus sequence defined by the $B o L A$ Nomenclature Committee was obtained using ClustalW2 from EMBL for determining the amino acid variations between the protein sequences of the two breeds mentioned above. The alignment of final protein sequences of Deoni and Ongole breeds along with the BoLA Consensus sequence is depicted in Fig 2. A similar polymorphism was also observed by Takeshima et al. (2002), who analyzed
PCR-SBT in a total of 176 Japanese Shorthorn cattle and identified 21 distinct alleles with different amino acid sequences in the translated BoLA-DRB3 alleles. The aligned amino acid sequences were in accordance with the detailed DNA sequence as reported by Russell et al. (2004). In a PCR based typing method, Takeshima et al. (2018) identified that South American Zebu cattle breeds had a gene diversity score and a nucleotide diversity score higher than 0.86 and 0.06 , respectively. Further, the authors observed that the historical divergence between Taurine and Zebu cattle breeds which may be due to their respective origin, selection and adaptation. The results could clearly explain that these Zebu and Taurine types had differences in BoLA-DRB3 gene exhibiting diversity.

\section{CONCLUSION}

PCR-RFLP and PCR-SBT are powerful techniques to detect polymorphism in the exon 2 of the BoLA-DRB3 gene. The amplified fragment of BoLA-DRB3.2 alleles was found to be highly polymorphic as revealed by the PCR-RFLP variant data. The number of RFLP variants and types of DNA sequences indicates the involvement of more than one allele in PCR amplified genomic DNA. In Deoni and Ongole breeds of cattle BoLA DRB3.2*6 (0.216) and *15 (0.225) are the most common alleles with the highest frequency. The amplified fragment of BoLA-DRB3.2 alleles was found to be highly polymorphic in both Deoni and Ongole (Bos indicus) breeds of cattle as revealed by the PCR-RFLP variant data. Further, exploring the inheritance pattern of the BoLA-DRB3 gene with large number of samples form this two breeds may further reveal the crucial role of the $B o L A-D R B 3$ gene in providing disease resistance. The observed alleleic varition may also be studied for its 
Comparitive Genome Sequence Analysis of Bovine Lymphocyte Antigen BoLA DRB3.2 Alleles in Deoni and Ongole...

association with the disease resistance in indigenous cattle by incorpoarting large sample size and from differnt indigenous cattle breeds to draw coclusion for the role played by BoLA DRB3 genes in combating the disease occurance.

\section{FUNDING}

This study was funded by the Department of Biotechnology, MINISTRY OF SCIENCE \& TECHNOLOGY, Government of India, under grant: BT/PR1234/ADV/90/119/2011.

\section{REFERENCES}

Borg, A.A., Pedersen, S.A., Jensen, H. and Westerdahl, H. (2011). Variation in MHC genotypes in two populations of house sparrow (Passer domesticus) with different population histories. Ecology and Evolution. 1: 145-159.

David, B.M., Ordoñez, D., Suárez, C.F., Vicente, B., Vieira, C., López-Abán, J., Muro, A., Ordóñez, I. and Patarroyo, M.A. (2020). Major Histocompatibility Complex Class II (DRB3) Genetic Diversity in Spanish Morucha and Colombian Normande Cattle Compared to Taurine and Zebu Populations. Frontiers in Genetics. 10: 1293.

De, S. and R.K. Singh. (2006). Identification of new MHC-DRB3 alleles from Indian (Bos indicus) cattle. Animal Genetics. 37: 605.

Dietz, A.B., Detilleux, J.C., Freemann, A.E., Kelley, D.H., Stabel, J.R. and Kehrli, M.E. Jr (1997) Genetic association of bovine lymphocyte antigen $D R B 3$ alleles with immunological traits of Holstein cattle. Journal of Dairy Science. 80 (2): 400-405.

doNascimento, C.S., Machado, M.A., Martinez1, M.L., da Silva, M.V.G.B., Guimarães, M.F.M., Campos, A.L., Azevedo, A.L.S., Teodoro, R.L., Verneque, R.D.S., Guimarães, S.E.F. and Oliveira. D.A.A. (2006). Association of the bovine major histocompatibility complex (BoLA) BoLA$D R B 3$ gene with fat and protein production and somatic cell score in Brazilian Gyr dairy cattle (Bos indicus). Genetics and Molecular Biology. 29: 641-647.

Duangjinda, M., Buayai, D., Pattarajinda, V., Phasuk, Y., Katawatin, S., Vongpralub, T. and Chaiyotvittayakul, A. (2009). Detection of bovine leukocyte antigen DRB3 alleles as candidate markers for clinical mastitis resistance in Holstein x Zebu. The Journal of Animal Science. 87: 469476.

Gelhaus, A.L., Schnittger, L., Mehlitz, D., Horstmann, R.D. and Meyer, C.G. (1995). Sequence and PCR-RFLP analysis of 14 novel BoLA-DRB3 alleles. Animal Genetics. 26: 147-153.

Gilliespie, B.E., Jayarao, B.M., Dowlen, H.H. and Oliver, S.P. (1999). Analysis and frequency of bovine lymphocyte antigen DRB3.2 alleles in Jersey cows. Journal of Dairy Science. 82: 2049-2053.

Giovambattista, G., Golijow, C.D., Dulout, F.N. and Lojo, M.M. (1996). Gene frequencies of DRB3.2 locus of Argentine Creole cattle. Animal Genetics. 27: 55-56.

Goszczynski, D.E., Ripoli, M.V., Takeshima, S.N., Baltian, L., Aida, Y. and Giovambattista, G. (2014). Haplotype determination of the upstream regulatory region and the second exon of the BoLA-DRB3 gene in Holstein cattle. Tissue Antigens.
83: $180-183$

Kumar, S., Stecher, G., Li M., Knyaz, C. and Tamura, K. (2018). MEGA X: Molecular Evolutionary Genetics Analysis across computing platforms. Molecular Biology and Evolution. 35: 1547-1549.

Maccari, G, Robinson, J, Ballingall, K., Guethlein, LA., Grimholt, U., Kaufman, J., Ho, CS., de Groot, NG., Flicek, P., Bontrop, RE., Hammond, JA. and Marsh, S.G. (2017). IPD-MHC 2.0: an improved inter-species database for the study of the major histocompatibility complex. Nucleic Acids Research. 4: 45(D1): D860-D864.

Maillard, J.C., Renard, C., Chardon, P., Chantal, I. and Bensaid, A. (1999). Characterization of 18 new BoLA-DRB3 alleles. Animal Genetics. 30: 200-203.

Mason, R.A.B., Browning, T.L., Eldridge and M.D.B. (2011). Reduced MHC class II diversity in island compared to mainland populations of the black-footed rock-wallaby (Petrogale lateralis lateralis). Conservation genetics. 12: 91-103.

Miller, S.A., Dykes, D.D. and Polesky. H.F. (1998). A simple salting out procedure for extracting DNA from human nucleated cells. Nucleic Acids Research. 16(3): 1215.

Miretti, M.M., Ferro, J.A., Lara, M.A. and Contel, E.P. (2001) Restriction fragment length polymorphism (RFLP) in exon 2 of the $B O L A-D R B 3$ gene in South American cattle. Biochemical Genetics. 39: 311

Newhouse, D.J. and Balakrishnan, C.N. (2015). High major histocompatibility complex class I polymorphism despite bottlenecks in wild and domesticated populations of the zebra finch (Taeniopygia guttata). BMC Evolutionary Biology. 15: 015-0546.

Ryman, N. and Jorde, P.E. (2001). Statistical power when testing for genetic differentiation. Molecular Ecology. 10: 23612373.

Rupp, R., Hernandez, A. and Mallard, B.A. (2007). Association of bovine leukocyte antigen $(B o L A) D R B 3.2$ with immune response, mastitis, production and type traits in Canadian Holsteins. Journal of Dairy Science. 90: 1029-1038.

Russell G.C., Davies, C.J., Andersson,L., Mikko,S., Ellis, S.A., Hensen, E.J., Lewin, H.A., Muggli-Cockett, N.E. and Poel. J.J.V.D. (1997). BoLA class II nucleotide sequences, 1996: report of the ISAG BoLA nomenclature committee. Animal Genetics. 28: 169-180.

Sievers. F., Wilm, A., Dineen, D., Gibson, T.J., Karplus, K., Li, W., Lopez, R., McWilliam, H., Remmert, M., Söding, J., Thompson, J.D. and Higgins, D.G.(2011). Fast, scalable generation of high-quality protein multiple sequence alignments using Clustal Omega. Molecular Systems Biology. 11;7: 539.

Sharif, S., Maillard, B.A., Wilkie, B.N., Sargeant, J.M., Scott, H.M., Dekkers, J.C.M. and Leslie. K.E. (1998). Associations of the bovine major histocompatibility DRB3 (BoLA$D R B 3$ ) alleles with the occurrence of disease and milk somatic cell score in Canadian dairy cattle. Animal Genetics. 29:185-193.

Starkenburg, R.J., Hansen, L.B., Kehrli, M.E.Jr. and Chester-Jones, H. (1997). Frequencies and effects of alternative DRB3.2 alleles of bovine lymphocyte antigen for Holsteins in milk selection and control lines. Journal of Dairy Science. 80 : 3411-3419. 
Takeshima, S., Nakai, Y., Ohta, M. and Aida, Y. (2002). Characterization of $D R B 3$ alleles in the MHC of japanese shorthorn cattle by polymerase chain reaction-sequence-based typing. Journal of Dairy Science. 85: 1630-1632.

Takeshima, S.N., Miyasaka, T., Polat, M., Kikuya, M., Matsumoto, Y., Mingala, C.N., Villanueva, M.A., Salces, A.J., Onuma, M. and Aida, Y. (2014). The great diversity of major histocompatibility complex class II genes in Philippine native cattle. Meta Gene. 2: 176-190.

Takeshima, S., Corbi-Botto, C., Giovambattista, G. and Aida, Y.
(2018). Genetic diversity of BoLA-DRB3 in South American Zebu cattle populations. BMC Genetics. 19: 33.

van Eijk, MJT., Stewart-Haynes, J.A. and Lewin, H.A. (1992). Extensive polymorphism of the BoLA-DRB3 gene distinguished by PCR-RFLP. Animal Genetics. 23: 483-496.

Zhang, X., Lin, W., Zhou, R., Gui, D., Yu, X. and Wu, Y. (2016). Low Major Histocompatibility Complex Class II Variation in the Endangered Indo-Pacific Humpback Dolphin (Sousa chinensis): Inferences about the Role of Balancing Selection. The Journal of Heredity. 107: 143-152. 